\title{
Quadruple Factors Interference and Its Effects on Quality of Outsourcing Testing: A Case Study
}

\author{
Mohammed Anan Hussein ${ }^{1}$, Samer Zein ${ }^{2}$ \\ ${ }^{1}$ Master of Software Engineering, Birzeit University, Palestine,moanan2012@gmail.com \\ ${ }^{2}$ Master of Software Engineering, Birzeit University, Palestine, szain@ birzeit.edu
}

\begin{abstract}
The share of IT companies in the global market has been increasing and many organizations are moving to outsource their software development projects to off-shore vendors. Recently, the IT sector in Palestine has been gaining much ground with many software development companies specializing in software development outsourcing services. Maintaining high-quality and robust software products has always been a key success factor in the outsourcing sector. Software testing is considered to be the main phase in which teams can assure high quality of software products. Therefore, we did an exploratory multiple-case study and this study involves four Palestinian software outsourcing companies of different domain. We provide insights about factors that affect the quality of software testing practice, and explore applied testing techniques, methods and confronted challenges. The results reveal that there is big attention toward software testing as software development companies are investing more effort, time, and technical resources into their quality assurance teams. Additionally, among the applied software testing methods, more attention needs to be directed towards test automation. Moreover, more theoretical and technical courses targeting software quality assurance should be included in national Palestinian universities' curriculum. Finally, we propose a new model that can help practitioners to enhance the quality of their outsourced software products.
\end{abstract}

Key words: Software Testing, Software Outsourcing, Automation Testing, Case Study.

\section{INTRODUCTION}

Recently, businesses are more dependent on software products and the industry is paying more attention to automating their business processes. Many companies are looking to reduce the cost of software development as much as they can and increase system reliability. This can be achieved by exporting their software development to offshore vendors. Around 50\% of the global IT market are using outsourcing [22]. Software development outsourcing is the activity of transferring functions and associated assets to an external supplier who provides agreed services for a specific time with qualified price [12].
The main purposes of outsourcing are to save cost, improved quality of services, and access to specialist expertise, free management time, and enhanced financial control [5]. There are many success factors which outsourcing activities focus on such as leadership activities, organizational learning, quality management, trust, customer satisfaction [26]. However, outsourcing has many risks which can lead to lack of success and negative impact of customer satisfaction. For instance, bad quality, less knowledge transfer and lack of communication between client and vendor [26].

Outsourcing companies in Palestine care a lot about the quality of software to reduce the failures. Therefore, software testing is an important part of any software projects. It confirms that software projects meet requirements and conduct tasks effectively and efficiently. Furthermore, software testing has many testing phases and it can be one of the expensive tasks for any project due to poor analysis of software, more maintenance, and errors that lead to extra expenses [15].

There are few researchers who have researched the Palestinian development company's practices due to the fact that the Palestinian IT sector is still small compared to other countries IT sectors [2]-[5]. Therefore, we were motivated to make an exploration study about software testing and how these companies adopted testing methodologies, tools and methods in their projects and how they confronted challenges. Our results revealed that there are many attention toward software testing by Palestinian outsourcing companies.

Additionally, companies apply a comprehensive set of testing methods, techniques, and testing tools. Further, this study shows that the percentage of automation is increasing but still relatively low due to many reasons such as time and cost constraints and this is lead that manual testing is still the dominant practice. What is more, we discovered that there is a gap between the industry and universities due to lack of testing courses in universities curriculum. Moreover, training and good management of technical teams are important factors, they play a role behind the quality of software. At the end, we build a suggestion model which describes the needs and challenges of software testing outsourcing. 
The structure of the paper consists of 6 sections and the rest of the sections appeared as follows. Section 2 presents the last studies about software testing and outsourcing. Section 3 presents the research methodology that we used. Our findings were shown in section 4. Section 5 presents the discussion of our results. At the end, we conclude the study in section 6 .

\section{LITERATURE REVIEW}

Rawanet al [5] in their research explore and understand the challenges and factors that affect outsourcing in Palestine. They revealed that Palestinian IT sector are growing and found that outsourcing quality is affected by some factors such as client satisfaction, cost and geographical distances location. Therefore, they proposed model about outsourcing in Palestinian IT sector to expand their work. Moreover, Zarour et al [3] increase awareness of how software companies deal with software effort estimation and confronted challenges. They show that effort estimation accuracy increases with companies which adopt outsourcing models compared with companies that work in the local area.

The success of software development outsourcing depends on many factors such as good leadership capabilities, quality management practices, successful training arrangements, and knowledge transfer activities. However, one of the biggest challenges that outsourcing companies face is customer satisfaction followed by domain unfamiliarity and project schedule [26], [22].

There are many previous surveys and studies which have revolved around various practices and issues about software testing outsourcing, their findings show that software testing is a very important phase in software validation and verification [13]. Testing phase is important due to many reasons: reduced cost and time, building software with high quality, ensuring that projects tasks work properly and being able to do all of the functions correctly [8]. Therefore, the management of software testing outsourcing projects need some guidance [11]. However, there are many challenges and barriers such as money, cost and lack of resources and expertise, available time for projects. Cost items can be divided into direct cost and indirect cost, which represent projects expenses [14], [17].

Moreover, universities do not consider software testing as part of their educational curriculum and there are many barriers behind the weakness of giving education and training such as budget and schedule constraints [10].

There are no studies about software testing in Palestinian outsourcing companies except the study by Samer et al [2] who identified the current testing techniques and challenges that they face in mobile applications in Palestinian companies. They revealed that testers and developers have low experience and skills on how to test and develop mobile applications and present some issues such as communications issues [27].

Additionally, there are many testing methods and types and many studies show that black box is slightly more dominantly used than white box testing method in software organization [9]. Also, manual testing is still the dominant and automated testing is limited. Further, unit testing is still little used while system and functional testing are used a lot [22].

Some studies show that system and acceptance testing are useful and important while usability, and security and Performance are the top three non-functional testing activities [16], [15].

These days, automation testing has become a solution for many companies due to many benefits such as reducing cycle time, decreasing testing costs in software development. It shows the positive effects on budgets and quality and carries out the testing tasks in effective ways. It is also considered a core component in agile development [23]. Furthermore, automation testing helps large organizations to expand their projects such as Google and Microsoft [24].

However, automation testing has maintenance costs and high implementation, sometimes is difficult to maintain and has significant failure and risk [20], [13]. Also, lack of testing management makes the automation process more complex and leads to failure. Furthermore, automation for small projects is too expensive due to setting up automation and make configuration can be too costly compared to the rest of the testing effort. Sometimes automation leads to extra effort and cost and could be even less effective than manual in detecting errors [24].

\section{RESEARCH METHODOLOGY}

We did an exploration research to gain in-depth understanding about software testing practices in outsourcing companies in Palestine and explored how they applied testing methods and techniques.

\subsection{Case Study Design}

The main goal of our research is to collect data and make an exploration study about software testing in outsourcing vendors and understand the factors that affect software testing. Therefore, we used case study which is the most suitable for this type of research. Case study depends on industry and plays a good role in defining theory and theme. It divided into single case and multiple case study and we applied multiple case studies due to it being considered more trustworthy and active than single case. It also gathered more data from cases and gave good descriptions about the characteristics of each case. However, it needs time and resources compared to the single case research, and case study shouldn't merge with statistical sampling and replications. Additionally, theoretical propositions approach assist us to know which data can be ignored and which data should be focused on [1].

Our research depend on multiple-case study design which can be shown in Figure 1 and inspired by Yin [1]

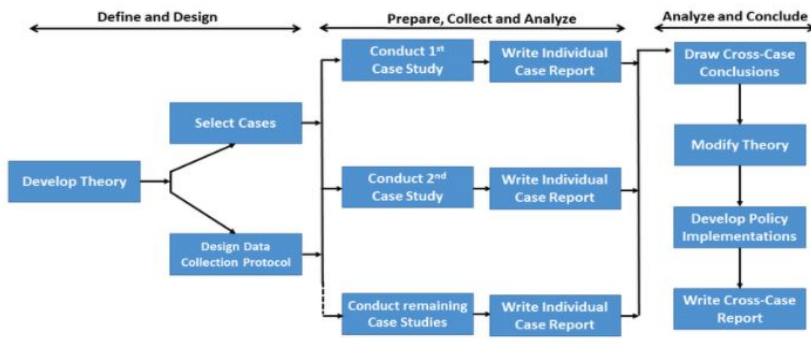

Figure 1: Multiple-Case Study Design 


\subsection{Research Questions}

Our main research questions are as follows:

- RQ1: To what extent do testing approaches influence the success rates of outsourced projects?

- RQ2: What are the currently applied testing methods and how effective they are?

- RQ3: To what extent do graduates of local universities possess the required knowledge in software testing techniques?

These questions assisted us to elicit data and collect them from interview questions that we used in our case studies .

\subsection{Data Collection Procedures}

In this study, our approach to do case study was based on collecting data through observations, interviews and focus groups. These methods are the source of our data that were collected to ensure case study construct validity through data triangulation [25]. Since we collect data from different sources and have qualitative research, data triangulation is the most suitable and helpful. It helps us to more quality data and also save them in places that would easily be reached by another researcher such as a document and spreadsheet.

In this study, we mainly relied on selecting cases based on the availability of team members, companies 'acceptance and readiness, personal relationships and past experience. We selected four Palestinian software companies which give outsourcing services and we called them $\mathrm{C} 1, \mathrm{C} 2, \mathrm{C} 3$ and $\mathrm{C} 4$. We made two focus groups and four single interviews with these cases. The first company $\mathrm{C} 1$ had one focus group and two single interviews. The other cases were also a single interview except $\mathrm{C} 4$ which was a focus group. Each interview consists of three parts. Firstly, we gave all of the participants an introduction about our research and why we selected them. Secondly, we asked them to introduce themselves and told us about their experience. Finally, all participants answered all of the interview questions and we collected all of the data.

Regarding interviews, some of the interviews were held online and the other were face-to-face. We applied semi-structured open ended design in our interviews and this approach was discussed by Hancock \&Algozzine [21]. We also conducted two focus groups, the focus group was with a group of participants due to the individuals gathered having common experience or sharing common views. Our role during the session was a moderator.

The first company was the only company which allowed us to collect information through observation. So, the process of observation was by taking notes on the behaviors and activities of participants of $\mathrm{C} 1$. All activity related to type of testing, testing tools, framework, methods that are used for recording and identifying bugs and challenges that they faced.

Before data analysis, we recorded all of the notes and data which discussed during the interviews and transcribed them in spreadsheets and documents using an identification code ${ }^{1}$ [7].

\footnotetext{
${ }^{1}$ Results of all the interviews and analysis are available on : https://github.com/MohammedHussein15/ThesisData
}

During the analysis, we used thematic coding approach to make analysis and it depends on giving each sentence special code and linking them to the original spreadsheet and document. Also, we spent three month during collecting all of the data from cases. Furthermore, our data was stored in documents which allow the other researcher to trace and retrieve [1], [19].

\subsection{Data Analysis procedure}

Since our research is qualitative research, we used thematic analysis due to it being a popular method and can be used to analyze research questions and datasets with different ways. It depends on finding the theme for data, label themes, organize them, analyze them, and report research papers. Thematic coding is a good method to analyze data in case study research methodology [1].

In our research, we applied thematic coding and followed steps which were suggested by Clarke and Braun [6].After we conducted all of the interviews, we familiarized all the data which was recorded, we created labels for the important features. Then we identified and searched suitable themes for our data. We review these themes and ensure that each theme has names. All of these processes were documented and saved them in spreadsheets. Figure 2 shows the steps of process that we have followed.

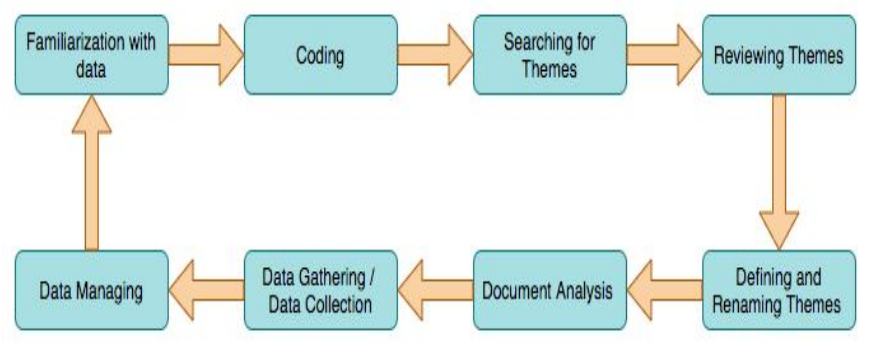

Figure 2: Data Analysis Steps

\section{RESULTS}

In our study, we include four different cases and we refer to them as $\mathrm{C} 1, \mathrm{C} 2, \mathrm{C} 3$ and $\mathrm{C} 4$. Each company has a different number of employees and we considered a company as a large company if they have more than 200employees. Further, if the companies have 70 to 200 employees, we call them as medium companies. However, companies which were less than 70 were considered small companies [5].

The first Case study (C1) which is a large company with multiple teams, it provides different software and hardware services. Teams there are specialized in developing web, mobile applications, network services and cloud systems. The second case study (C2) is considered as a medium sized company, it provides multiple solutions which relate to Hardware.

The third company (C3) offers digital marketing and sales solutions for the restaurant section and it is a medium size company. The last company $\mathrm{C} 4$ specializes in providing financial services to businesses customers. It's a small company that provides software services for United State and European companies. Table 1 shows all of the demographic data. 
Table 1: Cases Demographics Data

\begin{tabular}{|c|l|l|l|c|c|}
\hline $\begin{array}{c}\text { Case } \\
\text { ID }\end{array}$ & $\begin{array}{c}\text { Specializa } \\
\text { tion- } \\
\text { Provided } \\
\text { Services }\end{array}$ & $\begin{array}{c}\text { Compan } \\
\text { y Size }\end{array}$ & $\begin{array}{l}\text { International } \\
\text { Client } \\
\text { Locations }\end{array}$ & $\begin{array}{c}\text { Number } \\
\text { of } \\
\text { Intervie } \\
\text { wees }\end{array}$ & $\begin{array}{c}\text { Number of } \\
\text { Company } \\
\text { Employee }\end{array}$ \\
\hline C1 & $\begin{array}{l}\text { Software } \\
\text { Network }\end{array}$ & Large & $\begin{array}{l}\text { Taiwan } \\
\text { Israel } \\
\text { France } \\
\text { Ukraine } \\
\text { United States }\end{array}$ & 5 & 330 \\
\hline C2 & $\begin{array}{l}\text { Software } \\
\text { Hardware }\end{array}$ & $\begin{array}{l}\text { Mediu } \\
\mathrm{m}\end{array}$ & $\begin{array}{l}\text { Europe } \\
\text { United States } \\
\text { Israel }\end{array}$ & 1 & 120 \\
\hline C3 & Software & $\begin{array}{l}\text { Mediu } \\
\mathrm{m}\end{array}$ & United States & 1 & 75 \\
\hline S4 & Software & Small & $\begin{array}{l}\text { United States } \\
\text { Europe }\end{array}$ & 3 & 35 \\
\hline
\end{tabular}

Moreover, Table 2 presents the demographic data of each participant in the focus group and interview. It shows the role of each participant in their teams and number of experience years during their work and testing fields. Further, the table shows the highest academic degree and number of team members for each one. At last, it includes the gender of each one.

Table 2: Interviews and Focus Groups Participants Demographics

\begin{tabular}{|c|c|c|c|c|c|c|c|}
\hline $\begin{array}{l}\text { Case } \\
\text { stud } \\
\text { y ID }\end{array}$ & $\begin{array}{c}\text { Type of } \\
\text { Researc } \\
\text { h } \\
\text { Method }\end{array}$ & $\begin{array}{l}\text { Role in the } \\
\text { Team }\end{array}$ & $\begin{array}{c}\text { Experie } \\
\text { nce }\end{array}$ & $\begin{array}{c}\text { Testing } \\
\text { Experie } \\
\text { nce }\end{array}$ & $\begin{array}{c}\text { Highest } \\
\text { Academic } \\
\text { Degree }\end{array}$ & $\begin{array}{c}\text { Number } \\
\text { of } \\
\text { Team } \\
\text { Membe } \\
\mathbf{r}\end{array}$ & Gender \\
\hline $\mathrm{C} 1$ & $\begin{array}{l}\text { Focus } \\
\text { Group }\end{array}$ & $\begin{array}{c}\text { Senior QA } \\
\text { Team } \\
\text { Leader } \\
\\
\text { Senior QA } \\
\text { Team } \\
\text { Leader } \\
\\
\text { QA } \\
\text { Manual } \\
\text { Test } \\
\text { Engineer }\end{array}$ & $\begin{array}{c}11 \\
\text { years } \\
12 \\
\text { years } \\
2.5 \\
\text { years }\end{array}$ & $\begin{array}{c}11 \\
\text { years } \\
10 \\
\text { years } \\
2.5 \\
\text { years }\end{array}$ & $\begin{array}{l}\text { Bachelor } \\
\text { Bachelor } \\
\text { Bachelor }\end{array}$ & $\begin{array}{l}5 \\
3 \\
4\end{array}$ & $\begin{array}{l}\text { Female } \\
\text { Female } \\
\text { Female }\end{array}$ \\
\hline $\mathrm{C} 1$ & $\begin{array}{c}\text { Single } \\
\text { Intervi } \\
\text { ew }\end{array}$ & $\begin{array}{l}\text { Project } \\
\text { Manager }\end{array}$ & $\begin{array}{c}10 \\
\text { years }\end{array}$ & $\begin{array}{c}10 \\
\text { years }\end{array}$ & Bachelor & $\begin{array}{c}6 \text { Team } \\
\text { Leader } \\
\text { s, } \\
\text { Each } \\
\text { Team } \\
5-6\end{array}$ & Male \\
\hline $\mathrm{C} 1$ & $\begin{array}{c}\text { Single } \\
\text { Intervi } \\
\text { ew }\end{array}$ & $\begin{array}{c}\text { QA Team } \\
\text { Leader }\end{array}$ & $\begin{array}{c}10.5 \\
\text { years }\end{array}$ & $\begin{array}{c}5.5 \\
\text { year }\end{array}$ & Bachelor & 4 & Male \\
\hline $\mathrm{C} 2$ & $\begin{array}{c}\text { Single } \\
\text { Intervi } \\
\text { ew }\end{array}$ & $\begin{array}{c}\text { Technical } \\
\text { Team } \\
\text { Leader }\end{array}$ & $\begin{array}{c}10 \\
\text { years }\end{array}$ & $\begin{array}{c}10 \\
\text { years }\end{array}$ & Master & 7 & Male \\
\hline $\mathrm{C} 3$ & $\begin{array}{c}\text { Single } \\
\text { Intervi } \\
\text { ew }\end{array}$ & $\begin{array}{c}\text { QA } \\
\text { Manager }\end{array}$ & 4 years & 3 years & Bachelor & 14 & Male \\
\hline $\mathrm{C} 4$ & $\begin{array}{l}\text { Focus } \\
\text { Group }\end{array}$ & $\begin{array}{l}\text { Senior QA } \\
\text { Senior QA } \\
\text { Senior QA }\end{array}$ & $\begin{array}{l}8 \text { years } \\
8 \text { years } \\
8 \text { years }\end{array}$ & $\begin{array}{l}5 \text { years } \\
5 \text { years } \\
4 \text { years }\end{array}$ & $\begin{array}{c}\text { Bachelor } \\
\text { Master } \\
\text { Bachelor }\end{array}$ & $\begin{array}{l}6 \\
6 \\
5\end{array}$ & $\begin{array}{c}\text { Male } \\
\text { Male } \\
\text { Female }\end{array}$ \\
\hline
\end{tabular}

\subsection{Applied Testing Approaches}

In general, Quality assurance is important the same as development. Companies investigate different types and levels of testing to meet requirements, increase quality and reduce the errors that happened with different teams. There are many different types and levels of testing and each one has its objectives. In our study, all of the cases deal with many levels and apply many methods and try to apply as much as they can to make software without any bugs. Functional and non-functional testing are so important and include different types and all cases deal with them.

Additionally, software testing has many phases and all of the phases are important such as requirements, design and execution. Requirements come from different sources such as customers through sales and marketing teams and project managers, sometimes it comes from testing teams. Without analyzing and understanding the requirements correctly, there will be problems in the other phases. Testing teams have standards for testing and automation. New ideas come from product owners who suggest features, discover and buy new products. This is mentioned by C3: "We have a huge number of clients, each team of our company has a product owner who speaks with these clients. Product owners explain ideas for the teams about what are the new features and give suggestions. Sometimes clients ask for special features and QA teams approve features by asking clients if they care or not." -- QA Manager, C3.

In the same time, all cases try to do a full quality assurance process and full coverage percentage for test plans. At least, 90\% percent of test cases should be covered. There should be approval from QA teams and without approval releases will not be launched. Time management is so important for the testing process, at least 3 weeks to one month for doing all of the testing process. Further, one of the cases advise us that the tester and developer ratio should be 1:2.

There are many factors that stand behind the success of software testing outsourcing in any project such as time, good requirements, clear process, and factors related to team management, human resources and personality. This is highlighted by one of QA team leader in C1:"After good experience in software testing, there are many factors that depend on the success of projects such as if the team is qualified or not, bad time allocation, critical bug after production or from customer, poor testing and weak process. Moreover, check test plan if it is good or weak and if there are missing cases." -Senior QA Team Leader, C1.

\subsection{Testing Methods and Applied Tools}

The findings from our interviews revealed that all of the cases applied agile methods in their projects except C2. Agile methodology is important and beneficial for software testing and many companies applied it in their teams.Each project consists of many features and has many sprints and each sprint has different needed time.

Table 3 shows the summary of testing techniques that are applied in all cases and the main tools that help teams in their works. These tools are divided into communication tools, miscellaneous tools and test plan tools. 
Table 3: Tools and Techniques Applied in Software Testing

\begin{tabular}{|c|c|c|c|c|}
\hline $\begin{array}{c}\text { Case } \\
\text { Study } \\
\text { ID }\end{array}$ & $\begin{array}{c}\text { Communicat } \\
\text { ion Tools }\end{array}$ & $\begin{array}{l}\text { Tools } \\
\text { Used }\end{array}$ & $\begin{array}{l}\text { Test } \\
\text { Plan } \\
\text { Tools }\end{array}$ & Testing Techniques \\
\hline $\mathrm{C} 1$ & $\begin{array}{l}\text { Microsoft- } \\
\text { Teams } \\
\text { Slack }\end{array}$ & $\begin{array}{c}\text { Jira } \\
\text { Redmine } \\
\text { Jenkins }\end{array}$ & $\begin{array}{l}\text { TestLink } \\
\text { TestRay } \\
\text { Hp-Alm }\end{array}$ & $\begin{array}{l}\text { Manual, Automation, } \\
\text { Black-box, Load, } \\
\text { Performance Security Testing } \\
\text { Unit Testing for Automation } \\
\text { Code Review for Automation } \\
\text { Testing }\end{array}$ \\
\hline $\mathrm{C} 1$ & $\begin{array}{l}\text { Microsoft- } \\
\text { Teams } \\
\text { Microsoft- } \\
\text { Lync } \\
\text { Slack }\end{array}$ & $\begin{array}{l}\text { Redmine } \\
\text { Gerrit } \\
\text { Jenkins }\end{array}$ & Hp-Alm & $\begin{array}{l}\text { Manual, Automation, White- } \\
\text { box, Black-box, Sanity } \\
\text { Performance, Stress and } \\
\text { Security Testing } \\
\text { Code Review for Automation } \\
\text { Testing }\end{array}$ \\
\hline $\mathrm{C} 1$ & $\begin{array}{l}\text { Microsoft- } \\
\text { Teams } \\
\text { Microsoft- } \\
\text { Lync } \\
\text { Slack }\end{array}$ & $\begin{array}{l}\text { Redmine } \\
\text { GerritJen } \\
\text { kins } \\
\text { PowerPI }\end{array}$ & Hp-Alm & $\begin{array}{l}\text { Manual, Automation, Black- } \\
\text { box ,Rest-API, UI, Server } \\
\text { side, User Flow Testing } \\
\text { Code Review for Automation } \\
\text { Testing. }\end{array}$ \\
\hline $\mathrm{C} 2$ & $\begin{array}{c}\text { Skype, } \\
\text { RingCentral }\end{array}$ & $\begin{array}{c}\text { Jira } \\
\text { Github }\end{array}$ & $\begin{array}{c}\text { Google } \\
\text { Sheet }\end{array}$ & $\begin{array}{l}\text { Manual, Automation, Black- } \\
\text { box, Regression, Performance } \\
\text { Load Testing } \\
\text { Code Review for Automation } \\
\text { Some cases( play and records) }\end{array}$ \\
\hline $\mathrm{C} 3$ & $\begin{array}{l}\text { Microsoft- } \\
\text { Teams } \\
\text { Discord }\end{array}$ & $\begin{array}{c}\text { Jira } \\
\text { Jenkins }\end{array}$ & Zephyr & $\begin{array}{l}\text { Manual, Automation, Black- } \\
\text { box, Smoke, Performance } \\
\text { Testing } \\
\text { Load Testing for some } \\
\text { features. }\end{array}$ \\
\hline $\mathrm{C} 4$ & $\begin{array}{l}\text { Microsoft- } \\
\text { Teams }\end{array}$ & $\begin{array}{c}\text { Jira } \\
\text { Github } \\
\text { SourceTree } \\
\text { Postman }\end{array}$ & TestLink & $\begin{array}{l}\text { Manual, Automation, } \\
\text { Performance } \\
\text { Grey-box: Black-box + White- } \\
\text { box (API testing) } \\
\text { Integration, Sanity, Smoke, } \\
\text { Unit Testing for automation } \\
\text { Stress, Load, Security Testing } \\
\text { Code Review for automation } \\
\text { Testing }\end{array}$ \\
\hline
\end{tabular}

Table 4 shows automation percentage in all of the cases, tools used by each one and platforms.

Table 4: Automaton Tools and Percentage

\begin{tabular}{|c|c|c|c|}
\hline $\begin{array}{c}\text { Case } \\
\text { Study } \\
\text { ID }\end{array}$ & $\begin{array}{c}\text { Automation } \\
\text { Percentage }\end{array}$ & Automation Tools & Platform \\
\hline $\mathrm{C} 1$ & $40 \%$ & $\begin{array}{c}\text { Selenium Java } \\
\text { Appium }\end{array}$ & $\begin{array}{c}\text { Web } \\
\text { Mobile }\end{array}$ \\
\hline $\mathrm{C} 1$ & $30 \%$ & $\begin{array}{c}\text { Selenium Java } \\
\text { In-house framework } \\
\text { built-in python } \\
\text { UI Angular PHP- } \\
\text { Laravel }\end{array}$ & Web \\
\hline $\mathrm{C} 1$ & $40 \%$ & $\begin{array}{c}\text { Selenium Java } \\
\text { TestAssure }\end{array}$ & Web \\
\hline $\mathrm{C} 2$ & $30 \%$ & $\begin{array}{c}\text { TestComplete } \\
\text { Selenium Java } \\
\text { SoapUI }\end{array}$ & Web \\
\hline $\mathrm{C} 3$ & $35 \%$ & $\begin{array}{c}\text { Cypress } \\
\text { Appium }\end{array}$ & $\begin{array}{c}\text { Web } \\
\text { Mobile }\end{array}$ \\
\hline $\mathrm{C} 4$ & $25 \%$ & $\begin{array}{c}\text { Selenium UI C\# } \\
\text { RestSharp C\# }\end{array}$ & Web \\
\hline
\end{tabular}

\subsection{Teaching of Software Testing in Local Universities}

All cases share common things that students who come from local universities are very weak and have zero experience or knowledge about software testing. Even novice testers who come with initial experience have problems, sometimes they need training. According to $\mathrm{C} 3$ who said: "Sometimes testers who have one or two experience are weak and need more training, also fresh students need training before any interview or joining any team. "-- QA manager, C3.

Regarding testing courses, there are no courses in the universities which are specific for software testing except one university which gives a course called "verification and validation". There is a lack in the university's curriculums. There should be packages of course which support software testing such as C4 who advises universities to give ISTQB foundation level. All of the cases advise us to take courses related to automation and software testing principles, especially the basics of automation. Nowadays, new universities are thinking about entering testing courses. According to $\mathrm{C} 4$ who said: "Students are weak in general. In the last six month, I had interviews with almost 40 fresh students, just one university who focused on testing. Therefore, students who come from this university are good and others are so weak and don't know anything about testing. "-Senior QA, C4.

On the other hand, students care more about development and give more attention to development jobs. They said that these jobs gain more experience and salaries. This is confirmed by $\mathrm{C} 1$ who said: "Students are weak and they have misunderstandings about testing approaches and principles. They care more about development than testing and said that testing is not important and this is wrong. "-- QA Team Leader, C1.

In general, students who come from local universities don't have any experience, so training is so important to solve this issue. All of the cases give training for their fresh students and novice testers, except $\mathrm{C} 4$ who do not give any training and let the others depend on themselves. Furthermore, time is an important factor for training and topics of training too. So, some cases such as C3 give training for two month for the automation course and two weeks for a manual course. $\mathrm{C} 2$ gives two month training about software testing both automation and manual. Regarding C1, they have good programs which cover problems of testing, goals, approaches and methods. Some teams inside $\mathrm{C} 1$ give training practical tasks 1-2 month and others suggest good material for any fresh testers ten days for manual and one month for automation, UI and API testing. They train to hire and make them junior to be ready to join.

\section{DISCUSSION}

\subsection{Testing Approaches and Challenges}

Several insights can be concluded from the results related to software outsourcing testing and many factors play a good role behind the quality of software testing. In general, it was observed that the Palestinian industry is paying more attention to the needs of software testing. This can be shown by the number of testing projects being increased in the current period. We also noticed that Outsourcing companies care more about testing and give good budgets and resources unlike local, government and 
startups projects which don't care so much. Therefore, there are many factors for good software testing such as communication internally or externally. We observed that all of the cases suffer from bad communication between teams and this bad communication leads to misunderstanding and gaps between team members and increased coordination costs. Further, sometimes there are issues that come from the development side such as misunderstanding of the requirements clearly, less communication, low developer's experience and skills. Moreover, bad English language decreases the quality of the testing process since team members are communicated with each other especially from different cultures and countries. Therefore, to solve these issues, teams should make good analysis for requirements and hold more meetings and increase collaboration between teams and select students who have good English language skills. On the other hand, tester skills are so important and all of the cases advise that testers should have development skills and think like developers, object oriented and programming language's basics help to increase the quality. Further, cases suggest the number of testers regarding to developers ratio should be 1:2 and this came across with paper [18].

The results show good testing management and good requirement analysis will lead to successful projects. There are many testing phases and each phase has many processes and should be clear. Regarding cases, testing requirements and features come from customers through the marketing team and product managers, and sometimes the testing teams suggest some requirements. Requirements divide into features and stories, and each feature has a different number of positive and negative test cases. All of these things should be documented clearly with good details. Despite all of these processes, testing teams should execute at least $90 \%$ as coverage of any testing cycle.

Any testing team should consider many aspects and key challenges: time, resources, cost, and size of the projects, quality of tools, skills, salaries, high academic degree, environment, staffing and training (material and time). The result shows that time is a barrier and it plays a good role behind the quality of software testing. Moreover, a good environment reduces technical issues that outsourcing companies face. However, number of participants in our cases who have high degree are low and the salaries of testers in Palestinian companies are less than developer. Therefore, students prefer any development jobs more than testing.

\subsection{Lack of Automation Testing}

Based on the response of all interviewees and the results, manual testing is still in the dominant position versus automated testing. Percentage of Automation in outsourcing companies is less than manual due to many reasons such as time, cost and resources. All of the cases applied automation testing with low percentage and prefer manual due to manual testing is a good fit for smaller projects but if the number of team's increases and companies become bigger, manual testing will be hard. In addition, all of the cases deal with manual testing due to many reasons such as it is more flexible than automation testing and short-term cost is much lower with manual testing. With manual testing, results can be shown quickly and configuration for automation takes more time especially when changes come.
However, it was observed that teams face challenges when they apply manual testing due to test cases sometimes are difficult especially if they have some conditions and these conditions need time. Further, manual testing can be repetitive and boring and this lets testers leave their work if they don't change their position. Many testers have a hard time to stay engaged in this process, and errors are more likely to occur. Therefore, the quality of projects become low and this will lead to waste of time. The result shows that automation has many advantages and all of the cases prefer it due to running tests quickly and effectively. Companies prefer automation for long run projects, is more effective and saves money and time but is not good for short term run projects. It keeps technical minds involved and committed to the process. When the team is doing automation testing, the rest of the team can see results of testing easily, and allows more collaboration and a better final product. In General, it is more suitable for large projects. Moreover, all of the cases are using automation for web platforms which is common and some cases like $\mathrm{C} 1$ and $\mathrm{C} 3$ use mobile platforms. The results show that cases prefer to use the web platform selenium tool because it's free and open source and for mobile platforms is Appium. Additionally, the most programming language are used in Palestinian IT companies for automation is Java at variance C4 who use C\# language instead of Java. Further, some cases sometimes build their own framework such as $\mathrm{C} 1$.

\subsection{Software Testing Methods and Techniques}

Based on the result of all interviewees, most teams applied blackbox testing more than white-box testing. Low percentage of the outsourcing companies which apply white-box methods such as C1. In general, Black-box testing approaches are more popular than white-box testing. When teams apply this approach, testers don't need to know about the internal working of the software system and it focuses more on behavior. We noticed that not all of the cases apply unit testing and it is applied for automation code. Moreover, Non-functional testing is so important and it is applied such as Performance, load and security testing. We also noticed that integration testing is not applied so much and has difficulties sometimes. Therefore, it is done manually through debugging with a very basic scenario. Additionally, all of the cases are doing code review for automation code and it is an important technique for them and all of the cases use regression testing too. Furthermore, we can also notice that cases prefer to apply agile in their teams especially scrum framework.

\subsection{Software Testing In Local Universities and Importance of Training \\ It was noticed that the curriculum of local universities don't have} any courses specified for software testing except one university which gives a course called "validation and verification". Therefore, students who come from these universities have low experience and they don't have good knowledge about software testing. Unfortunately, universities' curriculum often neglect software testing courses, they prefer to focus on building software.

One of the important factors to increase and enhance quality of testing is increasing the percentage of training and all of the cases recommended this. Before the beginning of any software testing job, there should be good training for that job. It's essential for young testers to get their hands dirty with real testing work. 
There should be a map for the road of testing and a balance between theory and practice. Moreover, there should be training about the business environment, what the current projects are and what are the constraints and company culture and give good induction about making the person feel welcome. The results show that companies should prepare good training's material about software testing and give more exercises with many test cases and continuous feedback. Many cases in our study recommend positively ISTQB foundation level which can be beneficial for lecturers and industrialists. However, there are many challenges facing teaching software testing such as students don't prefer software testing due to it being boring, tedious and unnecessary tasks.

\subsection{The Proposed Model (Quadruple Testing Model)}

In this section, and based on our analysis of results and discussion, we suggest a conceptual model for building and enhancing software testing outsourcing in Palestine IT sector. The proposed model can help to increase the quality of software testing in outsourcing vendors and assist them in applying methods successfully.

There are many previous studies about testing but a few of them have models about software testing outsourcing such as "Conceptual Process Model". This model aims to increase awareness about the factors that influence the success of software testing outsourcing and understand the current practices of testing [8].Fig.3 shows the suggested conceptual model which can help the outsourcing vendors to do better and increase quality of software testing through software development life cycle. This model can be helpful for both researchers and testers who work in companies.

Quadruple Testing model consists of four factors: People, Organization, Software Development Process and Methods. These Factors have a relationship and depend on each other. The first factor is People factor, which consists of five elements: Personality of the testers and their relationship with the other teams. Good English language helps testers and teams to understand and make knowledge transfer especially if the other testers and teams come from different cultures. Moreover, communication internally and externally with different teams especially different culture. Finally, education level encourages testers to make more research about software testing and follow the latest testing practices that are applied in different outsourcing companies in other countries.

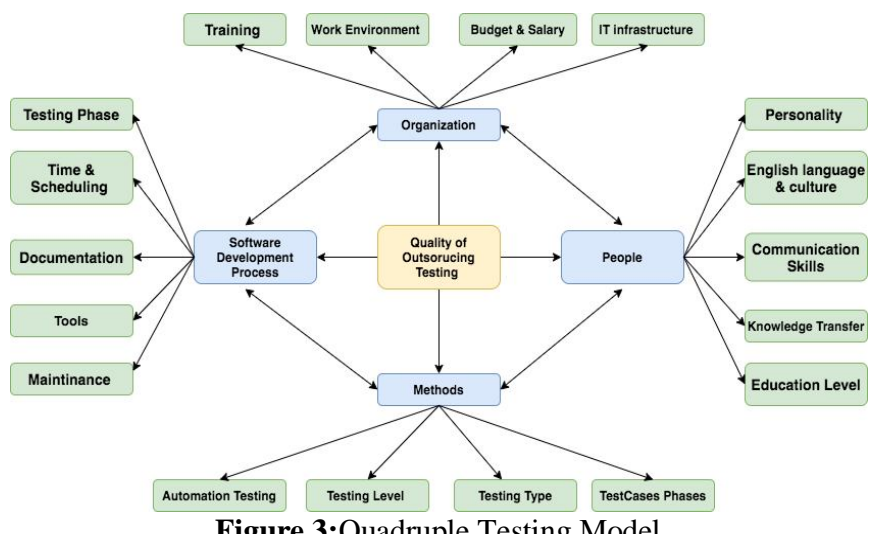

Figure 3:Quadruple Testing Model
The second factor is Organization, which contains four elements: Good training helps novice testers to get involved in work fast. Work environment is important that lets the other employees feel safe and not feel bored. If a company hasn't good IT infrastructure, it will face problems during the testing process, especially contact with teams from different countries. Budget and salary are so important, it encourages fresh students to choose software testing and do their best during work.

The third factor is the Software Development Process which contains four elements: Testing phases are so important and should be clear, these phases should be executed in specific time. Time is an important factor for software testing too. Moreover, all of the process should be documented from requirement, design into execution and everything should be reported between all of the team members. These processes will be executed using special tools and each phase has its special tools.

The last factor is Methods, this factor depends on good analysis and understanding requirements to help teams to do their work clearly and without any maintenance. It consists of four elements: Automation testing, Testing level (such as unit, integration, system and acceptance testing),testing type such as functional, non-functional, Black box testing, etc. Test Cases phases (design, management, risk, tools and reporting test cases).

\subsection{Threats of Validity}

The main goal of using reliability and validity is to gain more confidence and robustness results. In our paper, we applied three criteria and some tactics for these criteria [1]. The first one was construct validity which we used multiple sources of evidence and we established a chain of evidence. The second was external validity which we used theory based on literature research. Furthermore, for reliability we used case study protocol and developed a case study database. Despite all that, we believe that if more industrial cases were included in this study, more accurate findings could have been reached. Further, some bias may have been introduced during data collection by the first author.

\section{CONCLUSION AND FUTURE RESEARCH}

The current paper provides a study of software testing outsourcing in four different IT software companies in Palestine. The goal is to explore and understand the software testing process and the main factors and challenges that face these companies. This paper have observed that the numbers of projects that are related to software testing are increasing and Palestinian industry is paying more attention toward applying software testing methods in their teams. Software testing outsourcing provides more opportunities to both vendors \& donors from cost, time, mutual partnerships, future bonding, etc.

There are many testing methods and techniques that are applied. Manual testing is still in the dominant position versus automated testing. We revealed that the percentage of automation is increasing but is still low due to many reasons such as time and cost. We also found that there is a gap between universities and industry and education curriculum neglect software testing courses. Therefore, good training and good material are an important factor to increase the quality of software testing 
outsourcing. Additionally, we proposed conceptual model for the quality of software testing outsourcing, this model can assist Palestinian outsourcing vendors to open new testing teams and enhance process of testing. We called it "Quadruple Testing Model"

In future work, after reading many papers and exploring software testing, we wish to conduct research studies on the topic of the relationship between DevOps and software testing and go deep in the automation process and latest trends in software testing practices. Furthermore, to look for new methods in test case generation.

In our paper, we had limitations in the focus group with the number of participants. The number of participants should be six to eight participants in any focus group session, in our focus group we only had 3 participants [7].

\section{ACKNOWLEDGMENT}

We are very grateful to all participants for dedicating their time and attention to our research. We would like to express our gratitude and thanks all companies and their staff for their cooperation and facilitate our tasks.

\section{REFERENCES}

1. Robert K Yin. Case study research and applications: Design and methods. Sage publications, 2017.

2. Samer Zein, Norsaremah Salleh, and John Grundy. Mobile application testing in industrial contexts: an exploratory multiple case-study. In International conference on intelligent software methodologies, tools, and techniques, pages 30-41. Springer, 2015.

3. Ahmed Zarour and Samer Zein. Software development estimation techniques in industrial contexts: An exploratory multiple casestudy. International Journal of Technology in Education and Science, 3(2):72-84, 2019.

4. Ali Asfour, Samer Zain, Norsaremah Salleh, and John Grundy. Exploring agile mobile app development in industrial contexts: A qualitative study. International Journal of Technology in Education and Science, 3(1):29-46, 2019.

5. R. Khader and S. Zein, "Outsourcing in Palestinian IT Sector: A Qualitative Study," 2019 3rd International Symposium on Multidisciplinary Studies and Innovative Technologies (ISMSIT), Ankara, Turkey, 2019, pp. 1-9, doi: 10.1109/ISMSIT.2019.8932919.

6. Clarke, V., \& Braun, V. (2013). Teaching thematic analysis: Overcoming challenges and developing strategies for effective learning. The psychologist, 26(2), 120-123.

7. John W Creswell and J David Creswell. Research design: Qualitative, quantitative, and mixed methods approaches. Sage publications, 2017.

8. Ismail, Fatin \& Razali, Rozilawati. (2014). Contributing factors of successful software testing outsourcing. 2014

8th Malaysian Software Engineering Conference, MySEC 2014. 55-60. 10.1109/MySec.2014.6985988.

9. V. Vukovic, J. Djurkovic, M. Sakal i L. Rakovic, "An Empirical Investigation of Software Testing Methods and Techniques in the Province of Vojvodina", Tehnički vjesnik, vol.27, br. 3, str. 687696, 2020.

10. Kazerouni, Ayaan \& Shaffer, Clifford \& Edwards, Stephen \&
Servant, Francisco. (2019). Assessing Incremental Testing Practices and Their Impact on Project Outcomes. 407-413. 10.1145/3287324.3287366.

11. F. F. Ismail and R. Razali, "A Framework for Managing Software Testing Outsourcing Projects," J. Telecommun. Electron. Comput. Eng., vol. 9, no. 3, pp. 35-44, 2017.

12. Ahmed, Ahmedin \& Zhu, Weihua. (2011). Outsourcing software testing activities: A case study for Eastern Ocean Solutions (EOS) - China. 742 - 744. 10.1109/ICCSN.2011.6014196.

13. Deak, Anca \& Stålhane, Tor. (2013). Organization of Testing Activities in Norwegian Software Companies. Proceedings IEEE 6th International Conference on Software Testing, Verification and Validation Workshops, ICSTW 2013. 102-107. 10.1109/ICSTW.2013.18.

14. Latif, B., \& Rana, T. (2020). A preliminary survey on software testing practices in Khyber PakhtunKhwa region of Pakistan. Turkish Journal of Electrical Engineering and Computer Sciences, 28, 575-589.

15. Jahan, Muhammad Shah \& Riaz, Muhammad \& Ayub, Kashif \& Abbas, Muhammad. (2019). Software Testing Practices in the IT Industry of Pakistan. ECBS '19: Proceedings of the 6th Conference on the Engineering of Computer Based Systems. 110. $10.1145 / 3352700.3352724$.

16. Quesada-López, Christian \& Hernandez-Agüero, Erika \& Jenkins, Marcelo. (2019). Characterization of software testing practices: A replicated survey in Costa Rica. Journal of Software Engineering Research and Development. 7. 6. 10.5753/jserd.2019.472.

17. Vasanthapriyan, Shanmuganathan. (2018). A Study of Software Testing Practices in Sri Lankan Software Companies. 339-344. 10.1109/QRS-C.2018.00066.

18. Bhuiyan, s.M. Abdur \& Rahim, Md Shamsur \& Chowdhury, AZM \& Hasan, Md. (2018). A Survey of Software Quality Assurance and Testing Practices and Challenges in Bangladesh. International Journal of Computer Applications. 180. 10.5120/ijca2018917063.

19. Runeson, P. and M. Höst, Guidelines for conducting and reporting case study research in software engineering. Empirical software engineering, 2009. 14(2): p. 131-164.

20. Kumar, Divya \& Mishra, Krishn. (2016). The Impacts of Test Automation on Software's Cost, Quality and Time to Market. $\begin{array}{llll}\text { Procedia } & \text { Computer } & \text { Science. } & \text { 89. }\end{array}$ 10.1016/j.procs.2016.03.003.

21. Hancock, D.R. and B. Algozzine, Doing case study research: A practical guide for beginning researchers. 2006: Teachers College Press.

22. X. Xia, D. Lo, P. S. Kochhar, Z. Xing, X. Wang and S. Li, "Experience report: An industrial experience report on test outsourcing practices," 2015 IEEE 26th International Symposium on Software Reliability Engineering (ISSRE), Gaithersbury, MD, 2015, pp. 370-380, doi: 10.1109/ISSRE.2015.7381830.

23. Garousi, Vahid \& Mäntylä, Mika. (2016). When and what to automate in software testing? A multi-vocal literature review. Information and Software Technology. 76. 10.1016/j.infsof.2016.04.015.

24. Garousi, Vahid \& Elberzhager, Frank. (2017). Test Automation: Not Just for Test Execution. IEEE Software. 34. 90-96. 10.1109/MS.2017.34

25. June M Verner, Jennifer Sampson, Vladimir Tosic, NA Abu Bakar, and Barbara A Kitchenham. Guidelines for industriallybased multiple case studies in software engineering. In 2009 Third International Conference on Research Challenges in Information Science, pages 313-324. IEEE, 2009 
26. Majanoja, Anne-Maarit \& Linko, Linnéa \& Leppänen, Ville. (2017). Developing offshore outsourcing practices in a global selective outsourcing environment - the IT supplier's viewpoint. International Journal of Information Systems and Project Management. 5. 27-43. 10.12821/ijispm 050102.

27. Rimawi, Diaeddin\&Zein, Samer. (2020). A Static Analysis of Android Source Code for Design Pattern Usage. International Journal of Advanced Trends in Computer Science and Engineering. Vol 9 No.2. 2178 - 2186, doi: 10.30534/ijatcse/2020/194922020. 